\title{
Lei 10639/2003: reflexões sobre a cultura afro-brasileira e o uso de imagens nos processos educacionais escolares
}

\author{
Law 10639/2003: thoughts on the afro-brazilian culture and the usage of imagery in school and \\ educational processes
}

Ley 10639/2003: reflexiones sobre la cultura afrobrasileña y el uso de imágenes en los procesos
educativos escolares Recebido: 09/02/2021 | Revisado: 12/02/2021 | Aceito: 16/02/2021 | Publicado: 25/02/2021 Reginaldo Peixoto

ORCID: https://orcid.org/0000-0001-7452-7962 Universidade Estadual de Mato Grosso do Sul, Brasil E-mail: regi.peixoto77@gmail.com Suelem Ferreira dos Santos ORCID: https://orcid.org/0000-0002-8363-7917 Universidade Estadual de Mato Grosso do Sul, Brasil E-mail: susuneguinhaufms@ @otmail.com

\begin{abstract}
Resumo
O presente texto propõe uma discussão sobre o cumprimento da lei 10.639/03, cujo pressuposto na educação básica é a formação da consciência do aluno acerca dos processos históricos que retratam a presença do negro na história do Brasil e a sua contribuição para a formação da identidade nacional, historicamente negada em materiais pedagógicos como nos livros didáticos. Assim, por meio de uma pesquisa bibliográfica e documental, pretendemos afirmar que, desde o Período Colonial, a contribuição do negro foi importante para a construção da identidade cultural e para o desenvolvimento do nosso país e do nosso povo. Como ferramentas de aprendizagens, discutiremos o uso das imagens, visto que podem ser trabalhadas diariamente por professores, de modo a valorizar a história e a cultura, descontruindo preconceitos e discriminações que sobrevivem enraizadas na nossa sociedade, o que acaba por minimizar percursos históricos, papéis sociais e as contribuições do negro para a nossa nação.
\end{abstract}

Palavras-chave: Educação; Cultura afro-brasileira; Imagens; Ensino e aprendizagem.

\begin{abstract}
This paper aims to discuss the fulfillment of law 10.639/03, which commands in basic education the formation of students' consciousness regarding the historical processes that portray the presence of black people in Brazil's history and their contribution to the formation the country's national identity, which has been historically neglected in teaching materials such as textbooks/didactic books. Therefore, through a bibliographic and documentary research, we intend to affirm that, since the Colonial Period, black people's contribution has been pivotal in building cultural identity and towards the development of our country and our people. As learning tools, we shall discuss the usage of imagery, as they can be used by teachers in a daily basis, so as to enhance the history and the culture, tearing down prejudices and discriminations that are still deeply rooted in our society, something that ends up minimizing historical paths, social roles and black people's contribution to our nation.
\end{abstract}

Keywords: Education; Afro-Brazilian culture; Images; Teaching and learning.

\section{Resumen}

Este texto propone una discusión sobre el cumplimiento de la Ley 10.639 / 03, cuyo supuesto en la educación básica es la formación de la conciencia del estudiante sobre los procesos históricos que retratan la presencia de personas negras en la historia de Brasil y su contribución a la formación de la identidad. históricamente negado en materiales pedagógicos como en los libros de texto. Por lo tanto, a través de la investigación bibliográfica y documental, pretendemos afirmar que, desde el período colonial, la contribución de los negros ha sido importante para la construcción de la identidad cultural y para el desarrollo de nuestro país y nuestra gente. Como herramientas de aprendizaje, discutiremos el uso de imágenes, ya que los maestros pueden trabajarlas diariamente para valorar la historia y la cultura, deconstruyendo los prejuicios y la discriminación que sobreviven arraigados en nuestra sociedad, lo que termina minimizando los caminos y roles históricos. y las contribuciones de los negros a nuestra nación.

Palabras clave: Educación; Cultura afrobrasileña; Imágenes; Enseñanza y aprendizaje. 


\section{Introdução}

O presente trabalho infere uma discussão sobre o ensino de história da África e da Cultura Afro-brasileira a partir da proposição da Lei $n^{\circ}$ 10639/2003, assim como seu cumprimento nos processos educativos na Educação Básica. Assim, ao apresentarmos a escola como espaço de ensinar e, ensinar os percursos históricos por que passaram diversos grupos sociais, abordamos a temática afro como centralidade nesse trabalho, de modo que as práticas pedagógicas rompam com a segregação, maior visibilidade e participação do negro no contexto da sociedade brasileira.

Ao discutirmos os processos escolares e atenção que a escola deva dar à legislação educacional, defendemos que a legislação também seja um contributo pensarmos a formação da identidade nacional, a importância da participação do negro no contexto histórico, cultural, social e legal no Brasil.

Dessa forma, para cumprir o que por ora é proposto, discutimos as transformações que ocorreram no ensino de História no Brasil e a inserção da História Nova como movimento de realinhamento do ensino de história, cuja pertinência se baseia nos estudos históricos e nos processos de formação da identidade nacional que reconheça o negro como parte e, inclusive, importante desse processo.

O ensino de História pós LDBEN 9394/1996 (Brasil, 1996), não somente ganhou novas tessituras, como também novas temáticas, as quais podem ser enviesadas com outras áreas do conhecimento, como a Arte e a Literatura, conforme propõe a Lei 10639/2003 (Brasil, 2003).

Nessa perspectiva, ao nos atentarmos à importância da valorização e do reconhecimento do negro para o desenvolvimento da nossa história e do nosso país, ressaltamos que o professor pode utilizar diferentes ferramentas para o processo de ensino e aprendizagem, dentre elas, as imagens e imagens fílmicas, as quais podem tratar de várias dimensões socioculturais, inclusive asseverando a violência, a discriminação e o preconceito que, ao longo da História, o negro sofreu no Brasil.

Dessa forma, vale ressaltar que o professor enquanto facilitador dos processos de ensino e aprendizagem deve principiar a sua prática com respeito à diversidade, utilizando diferentes linguagens, pois isso acaba por inserir o aluno aos processos tecnológicos e em vivências mais humanizadas.

\section{Metodologia}

A pesquisa que apresentamos nesse artigo está sustentada sob a metodologia da pesquisa qualitativa de revisão da literatura, o que nos forneceu aporte teórico para as discussões e proposições que por hora apresentamos nesse escrito. Nesse sentido, as abordagens trazidas tanto da pesquisa documental, quanto da bibliográfica, possibilitaram afirmar os elementos históricos, o direito ao reconhecimento da cultura afro-brasileira e africana na educação básica e, ainda, algumas proposições de práticas pedagógicas a partir de recursos fílmicos, em prol de maior visibilidade ao negro, suas identidades e tradições, assim como a diminuição do preconceito e discriminação que ainda assolam a nossa sociedade e maltratam tantos sujeitos, principalmente os que possuem sua ancestralidade e raízes na África.

Quanto ao referencial teórico utilizado, nos embasamos em algumas legislações nacionais como Brasil (1996) e Brasil (2003), assim como algumas discussões apresentadas por Ribeiro (1995); Rüsen (2010); Roiz, D. S \& Santos, J. R. (2016) e tantos outros que defendem uma educação mais emancipadora e que reconheça a história do negro, sua contribuição cultural e algumas metodologias educacionais que, se bem utilizadas, podem contribuir para melhores práticas escolares, inclusão e ascensão social. 


\section{Resultados e Discussão}

A história do Brasil contada nas escolas nem sempre revela as trajetórias que os diferentes povos traçaram, assim como a participação que tiveram na construção da nação e na formação da identidade cultural. Muitas vezes, tal ensino se fundamenta na perspectiva do herói branco e do colonizador europeu, marginalizando grupos que ao longo dos tempos não se fizeram representados - foram marginalizados e invisibilizados.

A identidade Nacional, ou a construção desse conceito, segundo Fiorin (2009) surgiu no campo da literatura em 1836, com a abertura da corrente literária denominada Romantismo, onde os autores de obras, um tanto quanto nacionalistas, evidenciavam a braveza do indígena, a beleza da mulher negra e a autonomia feminina, como nas obras de ficção "O Guarani" de José de Alencar, "A Escrava Isaura" de Bernardo Guimarães e "Senhora" de José de Alencar, respectivamente.

Após a inclusão do negro e outros povos na literatura, trilhamos um grande caminho, talvez, nada romântico em se comparando aos aspectos da ficção e, somente no nosso século, é que negros e indígenas foram compreendidos como sujeitos inerentes aos processos históricos brasileiros e, dessa forma, incluídos nos discursos educacionais que fundamentam as organizações curriculares da educação básica pós LDBEN 9394/1996 (Brasil, 1996).

Certamente, além de admitirmos que o negro, assim como outros sujeitos foram amplamente responsáveis pela formação da nossa cultura e da nossa identidade nacional, cabe ressaltar que a história muita vez contada é ideológica e apregoa ênfase ao heroísmo branco, principalmente quando segrega o negro e o oculta dos vários momentos e fatos heroicos que marcaram a história desse país. Por isso, Silva Filho (2006) defende que a História do Brasil, assim como a história do negro na História dele precisam ser recontadas, pois quando a temática não é tratada pela escola, considerando fatos que são recorrentes para a vinda do negro, a forma como veio, a sua participação na construção da economia, da cultura e da identidade nacional, corremos o risco de, ao invés de educar, apregoar maior segregação, preconceito e discriminação.

A partir das ideias defendidas por Silva Filho (2006) e por decorrência das tantas lutas históricas do negro no Brasil, é que algumas políticas públicas foram implementadas de modo a garantir maior participação nos espaços sociais, como na educação básica, no ensino superior, nos concursos públicos, etc.

Com a promulgação da lei 10.639/2003 (Brasil, 2003), que estabelece as diretrizes e bases da educação nacional, para incluir no currículo oficial da Rede de Ensino a obrigatoriedade da temática "História e Cultura Afro-Brasileira", as questões acerca das trajetórias dos povos africanos e seus descendentes ganharam maior visibilidade, inclusive, posteriormente, quando houve a aprovação de outra Lei a 11645/2008 (Brasil, 2008), a qual além de ratificar o conteúdo da primeira, incluiu a temática indígena.

A partir da proposição de legislações específicas para tratar sobre a História e Cultura Afro-brasileira, houve maior empenho do sistema educacional para que tal direito fosse garantido, inclusive, deliberando diretrizes e incluindo as temáticas no currículos escolares e materiais de uso de professores e alunos, como no caso dos livros didáticos, marcados historicamente por um discurso histórico eurocêntrico que se fundamentava "na passividade diante da escravidão, por representações eurocêntricas, focada apenas nos aspectos folclóricos e culturais ou num tratamento da África como algo exótico" (Janz, 2014, p. 3).

Para Janz (2014), o ensino de História, a partir das proposições legais, ganhou nova roupagem. Certamente, muitos questionamentos surgiram por parte dos educadores, quando da aprovação da Lei 10639/2003 (Brasil, 2003), visto que exigiu novas metodologias, pesquisas e novas descobertas e passou a ressignificar o conhecimento que, até então, reduzia o papel do negro, assim como a sua participação na história dessa nação.

Quando se fala em África e Brasil e, principalmente nas instituições escolares, de imediato nos ocorrem recordações sobre a escravidão, nos vêm em mente os negros retirados a força de seu país de origem e trazidos para o cá em péssimas condições humanas - os estudos realizados em outrora nos remetem a temáticas sobre a Grécia, Roma, mudanças, revoltas, 
conflitos, guerras, etc., e nada - ou quase nada a respeito da África, suas culturas e seus povos que, juntamente com os europeus e os nativos, constituíram a história do Brasil (Janz, 2014).

De acordo com Schmidt (2012), a primeira cátedra de ensino de História no Brasil ocorreu em 1838, no colégio Pedro II e, até o fim dos anos de 1970, as modificações no ensino da disciplina foram restringidas pelo exemplo positivista sem utilidade. A partir dos anos de 1980, determinou-se um debate, entre diversas esferas empenhadas em rever as abordagens do campo historiográfico e seus desdobramentos sociais e didáticos.

Nesse sentido, a crescente produção acadêmica tendo como norte a História Nova, passou a fazer parte não somente dos debates em instâncias acadêmicas e representativas, mas ganharam visibilidade nos livros didáticos, inserindo abordagens históricas sociais, políticas, econômicas e estruturais dos conteúdos estabelecidos pelos documentos de orientações curriculares como os Parâmetros Curriculares Nacionais - PCN (Brasil, 1997), as Diretrizes Curriculares Nacional - DCN (Brasil, 2010) e, atualmente, a Base Nacional Comum Curricular - BNCC (Brasil, 2017).

Para Falcon (2002), aqueles alunos que frequentaram as instituições escolares até o fim da ditadura militar limitavam suas necessidades de aprendizagem a uma História positivista pautada na fixação de datas, nomes de ídolos, relações de presidentes, etc. Além do relevante prestígio do eurocentrismo na História Geral e a valorização dos dirigentes e do país na História brasileira. No processo de ensino e aprendizagem que se realizava na instituição escolar, não se encontrava margem para comentários e presença de pessoas mais simples da sociedade nos acontecimentos históricos.

No decênio de 1980, período de grandes fervores sociais e aprovação da nova Constituição (Brasil, 1988), diversas ações e diálogos foram executados pelos movimentos negros, todavia, além de garantir maior participação e visibilidade social como a exemplo de outros grupos, como os trabalhadores, o intuito era de adicionar na parte educacional da recente constituição, ações, objetivando a batalha contra o racismo. Já nos anos de 1990, por intermédio da historiografia francesa, nos deparamos com a presença relevante da Nova História nos livros didáticos e nas salas de aula, o que passou a denominar-se História Temática. Tais mudanças contaram com o apoio dos educadores brasileiros, os quais reescreveram uma nova página do ensino de História e ampliação da produção de pesquisas campo adentro.

Desde o ano de 1980, vários estudiosos como Schmidt (2005) vêm realizando estudos e discussões a respeito do ensino da História e dos problemas propostos pelos Parâmetros Curriculares Nacionais (PCN) (Brasil, 1997). Dentre essas discussões encontra-se o debate acerca da batalha contra o preconceito racial e o ensino da História da África.

Ministrar um ensino de História, tendo como foco a valorização da História da África aos discentes do Brasil é a forma eficaz de ruptura com a sustentação eurocêntrica que definiu a constituição educacional no Brasil. Com a aprovação da Lei 10639/2003 (Brasil, 2003), exigindo o ensino da História dos afro-brasileiros e africanos no ensino básico, percebeu-se a necessidade de sua efetivação, principiando com certas restrições, porém, os educadores até então não haviam vivenciado em suas licenciaturas, proximidade com matérias específicas a respeito da história da África, contudo, a maior parte dos livros de história, usada tanto na educação básica quanto na superior, não guardara para a África lugar próprio, os discentes passam a idealizar somente estereótipos a respeito da África e seu povo, o que reafirmou a necessidade de um amplo processo de formação continuada para atuação no campo (Bittencourt, 2017).

O negro tratado pela história, ao longo dos tempos, representou a escravidão, foi rotulado e estereotipado e, na maioria das vezes, reduzido a marginal. Numa visão historiográfica que se distância do ensino tradicional de História, nas últimas décadas o negro vem passando pelo crivo do reconhecimento social, do sujeito que contribuiu com a sua força de trabalho para a construção desse país, da sua economia, da sua cultura e da sua identidade. Embora muitas práticas escolares ainda se encontram pautadas em uma história minimizadora. (Correa, 2000, p. 87 apud Fonseca 2007, p. 14). 
Nesse contexto de avanços nos estudos históricos e, com a consolidação dos procedimentos de liberdade e evolução das investigações da história em relação ao continente africano e de seus habitantes - pensamento iniciado a partir da segunda metade do século XX, passou-se a refletir, ao mesmo tempo, sobre outra perspectiva que buscava:

[...] o reconhecimento da importância do papel da África na história da humanidade e tentava desconstruir os olhares preconceituosos/ racistas e as imagens negativas elaboradas até então sobre os africanos e as populações afroamericanas [...] esses estudos passaram a ser utilizados com uma intensidade desconcertantes na invenção de uma nova imagem dos africanos, contribuindo de forma inconfundível no quadro de redefinição da auto-estima e da inserção político social das populações africanas e afro-americanas, em África, nas Américas e na Europa (Oliva, 2005, p. 74).

A formação histórica do Brasil apresenta, dentre outros princípios, uma forte relação com a África, visto que de lá foram trazidos os negros para aqui serem convertidos em mão-de-obra escrava, portanto, transportaram para a nossa terra os seus hábitos, seus costumes, suas crenças e valores. Contribuíram assim, grandemente para a constituição cultural e social da população brasileira.

Os ensinamentos da história e cultura africana na escola, na atualidade e, enviesados pela Lei 10639/2003 e $11645 / 2008^{1}$ se associam à realidade daquele continente com a realidade social brasileira, para então evidenciar as identidades que constituem a nossa formação cultural e social. Tais aspectos da cultura africana se dissolveram em meio à cultura europeia e indígena, configurando um novo jeito humano de ser - o brasileiro (Ribeiro, 1995).

Sendo assim, autores como Ribeiro (1995) e Leite (2007) defendem que as diversas relações que unem o Brasil ao continente africano, como as práticas religiosas, a música, a dança, a oralidade, a culinária, o artesanato, as técnicas agrícolas, a linguagem, entre outras, nos faz um povo único, mas que historicamente, dependente de valores e costumes africanos, os quais se mantém na nossa história e na nossa formação identitária.

A lei 10639/2003 (Brasil, 2003) foi estabelecida para assegurar o reconhecimento ao afro-brasileiro com o intuito de promover a cidadania e a igualdade racial, por intermédio de práticas educacionais que atribua valor ao "outro". Ela colabora, assim, para quebrar o silêncio histórico a respeito da cultura e história do povo negro brasileiro. Nesse entendimento, Gomes (2008) assegura que a Lei aponta direcionamentos para a constituição de uma educação antirracista nos espaços de educação formal, transpondo as regras discursivas centradas no povo europeu. Dessa forma, a aplicação da lei no Sistema Nacional de Ensino Básico ocasiona em abrir o ambiente escolar para tornar licito falar a respeito da exclusão e marginalização de uma esfera social, cuja história por muito tempo foi negada ou tratada de forma europeizada.

Os afro-brasileiros foram importantes na constituição da sociedade e na construção da formação do povo brasileiro, juntamente com outros povos e outras etnias. Eles colaboraram na construção de uma sociedade que passou por diversas transformações, principalmente no decorrer do século XIX, marcado por diferentes acontecimentos históricos: Independência do Brasil, em 1822; a organização do Estado nacional, que incentivou a política de imigração para o nosso país e, consequentemente, a substituição do trabalho escravo pelo trabalho livre; a difusão da ideologia do branqueamento; a abolição da escravidão, em 1888; e o advento da República em 1889. Estas transformações não garantiram a inclusão dos ex-escravos negros no mundo do trabalho, ao contrário, foram excluídos socialmente (Lopes, 2006).

A libertação chegou, mas não proporcionou aos negros o acesso aos bens produzidos nesse sistema histórico, como terra, moradia e educação, para garantir uma condição de vida digna. Os ex-escravos negros começaram uma nova batalha, que era de sobreviver diante de tantas desigualdades sociais e combater o racismo na sociedade brasileira.

\footnotetext{
${ }^{1}$ A Lei 11645/2008 foi aprovada com o intuito de, além de ratificar a obrigatoriedade sobre o ensino da História e Cultura Africana e Afrobrasileira na educação básica, acrescida da temática indígena, já que na compreensão dos movimentos sociais, os nativos também foram invisibilizados e discriminado pela história tradicional brasileira.
} 
Ainda que estudos sobre o negro, suas condições e importância tenham avançado, ainda há um longo caminho que os profissionais da educação precisam percorrer para que não caiam nas armadilhas da ingenuidade em acreditar na neutralidade do seu trabalho. Por isso é mister compreender a importância de sua prática educativa, de suas ações e de sua postura diante da diversidade cultural. Além de inserir novos conteúdos no currículo escolar, para efetivação da Lei 10.639/03 (Brasil, 2003) é fundamental questionar e desconstruir os conhecimentos sociais já instituídos nos currículos escolares, seja nas ações didáticas dos materiais institucionalizados como o livro didático, ou na promoção de outras ferramentas, como o uso de imagens, conforme passamos a discutir.

O ensino de História, assim como de outras disciplinas na educação básica, exige, além da compreensão dos conteúdos de ensino, o uso de metodologias que atendam às perspectivas dos alunos, sujeitos dinâmicos, inseridos numa era tecnológica, onde os diferentes recursos podem contribuir com suas expectativas escolares (Candau, 2016).

Ao propormos uma didática pautada na perspectiva da História Nova, defendemos que o professor precisa romper com as velhas práticas e promover o protagonismo discente, inserindo o aluno no processo de ensino e aprendizagem, por isso, a educação precisa dialogar e se aproximar das vivências dos sujeitos escolares, tanto nos discursos, quanto com o uso de ferramentas, pois grande parte dos alunos se encontram conectados a vários recursos e equipamentos como: redes sociais, netflix, smartfhones, tablets, etc., tanto para se comunicar, como para lazer ou realização de estudos.

Diante do que afirma Rüsen (2010), no decorrer das discussões, leituras e das observações sobre as temáticas afro em sala de aula, é preciso promover uma consciência histórica, onde o aluno além de compreender as trajetórias do negro na história, perceba sua importância e a sua participação nas vivências sociais. Tais ações podem ser trabalhadas por meio da leitura de imagens.

De acordo com Michel de Certeau (1997) a análise de imagens deve ser necessariamente complementada com o estudo daquilo que o "consumidor cultural" elabora, constrói e define com tais imagens em seu cotidiano. Segundo Burke (2004), o consumo de imagens é cada vez mais generalizado e propagado pelos meios de comunicação e pelos diversos tipos de tecnologias, por isso, o uso desses instrumentos no processo de ensino e aprendizagem é uma estratégia bastante pertinente e essencial para melhorar e fundamentar a compreensão, assim como, despertar e manter a atenção dos discentes, no que se infere aos conteúdos ministrados e quanto aos personagens históricos apresentados.

Roiz e Santos (2016) afirmam que as cenas de filmes que são selecionadas para expressarem uma determinada temática e sua continuidade no tempo pode muito bem servir para instigar o estudo e a implementação da Lei 10639/2003 (Brasil, 2003) em sala de aula, muito embora a questão histórica e sua apresentação no enredo não seja o ponto culminante numa produção cinematográfica - nem por isso os filmes devem deixar de fazer parte constitutiva do processo de ensino e aprendizagem.

No que diz respeito ao cinema, as cenas fílmicas se utilizadas de maneira correta, servem para persuadir e instigar os discentes a refletir historicamente com maior eficácia o tema em questão, pois estamos lidando com uma "geração" formada muito mais por imagens e imagens em movimentos, do que simplesmente por textos escritos (Roiz e Santos, 2016). Não se trata de negar o valor que os textos possuem, assim como sua contribuição para a aprendizagem, mas sim admitir que utilização de recursos pedagógicos diferenciados contribui de modo a proporcionar a melhoria nas estratégias de ensino e aprendizagem dos discentes da educação básica, por isso mesmo, é favorável que o docente associe textos com imagens, o que possivelmente, possibilita o estudo da história mais concreta e real, portanto menos abstrata.

Ao partirmos da consideração de que o papel da escola é o de formar cidadãos críticos, participativos, que respeitem e valorizem as individualidades e as diferenças sem fazer destas um processo de discriminação e exclusão, observamos a necessidade de a escola ser um espaço da multicultura, do respeito e da valorização da diversidade, pois nela se encontrar 
diferentes culturas, diferentes formas de vivenciar a sexualidade, a religião, as expectativas pessoais, etc., por isso ela pode ser reconhecida como um espaço de representação da sociedade que está fora dela (Candau, 2016).

Sendo assim, o uso de imagens, quando bem discutidas e analisadas, pode reduzir as barreiras impostas pela educação da desigualdade e contribuir na formação de discentes críticos e conscientes de seu contexto histórico e seus papéis sociais, preparados para agir, interagir e transformar esse contexto, favorecendo então a valorização da cultura e da história afrobrasileira. Para Hernándes (2000), o uso de imagens em sala de aula pode ser uma prerrogativa para trabalhar qualquer temática.

Abordar a diversidade cultural, mesmo em época de crise política e de não promoção de políticas públicas - como na atualidade, significa contribuir para a articulação de trocas de diálogos que produzam o respeito a uma cultura de iguais, mesmo que diferentes entre si. É importante compreender que tal cultura precisa ser pensada no contexto escolar, como aprendizado, como estratégia de conhecimento humano, pronta a se posicionar frente às diferenças e as desigualdades, cada vez mais observadas e perceptíveis, com um ensino sempre enviesado com as diretrizes curriculares e a legislação educacional, como no caso das leis que implicam a inserção da história da África e da cultura afro-brasileira na educação básica (Brasil, $2003 ; 2008)$.

Segundo Silva (2006), a diversidade cultural precisa ser vista pelos educadores como uma diversificação de grupos sociais, pois ela inclui não somente a raça e o sexo, mas também grupos étnicos, região de origem, idade etc., sendo definida como um mix de pessoas com identidades diferentes interagindo no mesmo sistema social, nesse caso a escola. Por isso os recursos imagéticos são bastante pertinentes, pois revelam espaços, grupos sociais, diferenças de gêneros, cor da pele, etc.

Quando consideramos as mudanças nas políticas educacionais brasileiras, podemos afirmar que a Lei 10.639/03 (Brasil, 2003) causou impactos na subjetividade de negros e brancos, pois de acordo com Gomes (2008) do ponto de vista pedagógico a superação dos preconceitos sobre a África e o negro no Brasil poderá impactar processos humanos positivos e proporcionar uma visão afirmativa acerca da diversidade étnico-racial, entendendo-a como uma riqueza da nossa diversidade cultural e humana, já do ponto de vista político essa mesma visão deverá sempre ser problematizada à luz das relações de poder, dominação e dos contextos de desigualdade e de (des)colonização.

Roiz e Santos (2016) afirmam que o uso das imagens em sala de aula pode tornar menos abstrato o estudo da história, ao mesmo tempo em que contribui para o aluno relacionar passado e presente, ou presente e passado, em suas reflexões, pois as imagens possuem recriar espaços, personagens e momentos históricos, portanto, elas têm muito a dizer.

As imagens, dada sua integração, principalmente nos campos midiáticos, podem ser encontradas com muita facilidade. A ampliação do uso de recursos tecnológicos, como a internet, por exemplo, nos coloca em contato com revistas, jornais, filmes, textos imagéticos, obras de arte, etc. Por isso o uso desses recursos pode ser incluído com maior facilidade nas aulas de história, ou de quaisquer outras disciplinas, no entanto, se faz necessário que o professor desenvolva um estudo prévio, para conhecer e reconhecer os recursos a serem utilizados por ele (Litz, 2009). Todo e qualquer material a ser mostrado, discutido e problematizado em sala de aula, exige uma análise prévia pelo docente, ainda que seja encontrado em sites ou outros materiais confiáveis, como livros e revistas, por exemplo.

Para Candau (2016), é importante que os materiais utilizados em sala de aula sejam de fácil compreensão para os alunos e levem os mesmos a se posicionar como sujeitos participantes do processo de ensino e aprendizagem. No caso dos filmes, fotografias, ou outras mídias digitais, tais recursos podem ser acessados pelos próprios discentes, a partir do uso de salas de informática, ou até mesmo seus aparelhos celulares - sempre em prol do conhecimento escolar e da humanização do sujeito humano.

Nessa prerrogativa da utilização das imagens como material pedagógico, acreditamos que o uso de imagens em sala de aula cumpre ao que é emanado da legislação educacional, quando apregoa que a cultura afro-brasileira deve ser trabalhada 
nas disciplinas de História, Arte e Literatura, as quais fazem parte constitutiva do currículo escolar e do processo ensinoaprendizagem no contexto da educação básica (Brasil, 2003; 2008).

Nesse sentido, Gomes (2008, p. 68) pontua que:

A partir da Sanção da Lei 10.639/03 e aprovação da Resolução 1, de 17/03/2004, que instituiu a Diretrizes Curriculares Nacionais para a Educação das relações Étnico-raciais e para o Ensino de História e Cultura afroBrasileira e Africana, é que as escolas da educação básica passam a ter um documento legal que discute e aprofunda o teor da referida lei, capaz de orientar a prática pedagógica.

Abordar os aspectos legais da educação nas práticas pedagógicas é, sem sombra de dúvidas, extrapolar os discursos que, muitas vezes, são enviesados na marginalização do negro, tanto na história, quanto nas representações sociais principalmente na atual conjuntura política, onde se vislumbra uma forte rejeição às políticas de inclusão e da valorização das minorias. A escola pode fazer muita diferença ao se posicionar em favor da diversidade e em respeito à legislação educacional.

As discussões sobre a História da África e sobre Cultura Afro-brasileira podem envolver outros sujeitos que não somente os professores de História, ou as demais áreas de abrangência da Lei 10639/03 (Brasil, 2003), mas sim todos os setores, os profissionais das escolas e também a comunidade externa dela, pois além de o conteúdo ser diariamente trabalhado como elemento do currículo, pode ainda ser desenvolvido em forma de projetos interdisciplinares.

Apesar de não ser mais novidade que muitas políticas reforcem a importância de trabalhar a história dos povos africanos, suas identidades, suas culturas e suas contribuições para a formação e afirmação da identidade brasileira, é possível perceber a existência de barreiras para o desenvolvimento deste tema em sala de aula, o que pode ocorrer em função da concepção histórica enraizada em nossas consciências e em nossa própria cultura construídas desde a colonização. Por isso defendemos que as aulas de história sejam enviesadas pelas teorias da História Nova e que os recursos de ensino e aprendizagem sejam os mais diversos possíveis, dentre eles os digitais, como a exemplo das imagens fílmicas.

\section{Considerações Finais}

A história da educação no Brasil resguarda registros que demonstram que o negro, ao longo do tempo, foi lembrado apenas na perspectiva do sujeito traficado, escravizado e passivo. Os livros de história há muito apresentam os heróis da nossa gente como sendo aqueles que venceram grandes batalhas, conquistaram territórios, ou lideraram movimentos, inclusive, são homens brancos, do gênero masculino.

A presença do negro na história do Brasil se confunde com o nosso processo de colonização, pois data das primeiras décadas após o descobrimento, o que importa dizer que seu papel foi tão importante quanto dos outros sujeitos que colaboraram para a construção da nossa nação, como os índios e os portugueses.

A ideia de construção de identidade nacional e de reconhecimento do negro no nosso processo cultural e identitário apregoam do Romantismo Brasileiro no século XIX, quando diversos artistas literários como Bernardo Guimarães já inseriam em sua obra de ficção, a figura forte do negro, como um ser destemido e lutador pela sua aceitação no meio social. Por isso a literatura foi uma forte aliada quando mostrou os contextos de vivência e as relações entre os negros, os índios e os europeus naquele período, considerado por Leite (2007), como o "pontapé" inicial para a formação do caráter nacional brasileiro.

A luta dos negros não é algo tão recente e tão presente na nossa história, pois ainda que ela ocorresse, durante muito tempo foi invisibilizada, o que acabou por ocultar valores históricos e culturais sobre a África e o seu povo, o que somente veio a ser resolvido por meio de políticas educacionais, como da aprovação da lei 10.639/03 (Brasil, 2003).

No que diz respeito à educação, a aprovação da lei 10.639/03, além de estabelecer a história da África e da cultura afro-brasileira como conteúdos inerentes ao currículo escolar, corroboraram também para que as práticas pedagógicas fossem 
repensadas, visto que na contemporaneidade, o uso das tecnologias aproximam o campo educacional das diversas mídias: imagens, filmes, fotografias, etc., por isso defendemos que as práticas pedagógicas se contemplem dessas ferramentas para maior aprendizagem dos educandos.

Nesse sentido, afirmamos que trabalhar as áreas de história, arte ou literatura na escola, passa pela necessidade de reconhecer o negro como sujeito da nossa história, como contribuidor da formação da nossa identidade cultural, por isso necessitamos olhá-lo sem rótulos e estereótipos e, as imagens, no entanto, podem dizer muito e contribuir para uma aprendizagem mais prazerosa, mais humanizada e menos segregadora - depende de cada um de nós, educadores.

Importa ainda registrar que, este estudo, mesmo que teórico e breve, poderá contribuir para leitura de pesquisadores iniciais, professores, acadêmicos e outros leitores que se interessam pelo tema. A temática é ampla e, embora muito tem se debatido e pesquisado sobre a história da África, dos negros e da formação da identidade nacional brasileira, há um longo percurso a percorrer, pois o preconceito e a discriminação permanecem fortes e vivos na nossa sociedade.

\section{Agradecimentos}

À Pró-Reitoria de Pesquisa e Pós-Graduação da UEMS e ao Programa de Pós-Graduação, Mestrado em Educação, Unidade de Paranaíba - MS.

\section{Referências}

Brasil. (2017). Base Nacional Comum Curricular. Brasília: MEC. http://basenacionalcomum.mec.gov.br/images/BNC C_20dez_site.pdf.

Brasil. (2003). Lei 10.639/2003, de 9 de janeiro de 2003. Altera a Lei $n^{o}$ 9. 394, de 20 de dezembro de 1996. Brasília: Planalto. http://www.planalto.gov.br/ccivil_03/leis/2003/110.639.htm.

Brasil. (2008). Lei 11.645/08 de 10 de março de 2008. Brasília: MEC. http://portal.mec.gov.br/index.php?option =com_docman\&view=download\&alias=10101-lei-11645-10-03-2008\&Itemid=30192.

Brasil. (1996). Lei de Diretrizes e Bases da Educação Nacional. Lei número 9394, 20 de dezembro de 1996. Brasília: MEC. http://portal.mec.gov.br/seesp/arquivos/pdf/lei9394_ldbn1.pdf.

Brasil. (1988). Constituição Federal de 1988. Brasília DF: Planalto.

Burke, P. (2004). Testemunha ocular: história e imagem. Edusc.

Candau, V. M. (2016). Cotidiano escolar e práticas interculturais. Cadernos de Pesquisa 46(161), 802-820. http://www.scielo.br/pdf/cp/v46n161/1980-5314cp-46-161-00802.pdf.

Certeau. M. (1997). A cultura no plural. Papirus.

Dosse, F. (2013). Renascimento do acontecimento: um desafio para o historiador: entre Esfinge e Fênix. Editora UNESP.

Fiorin. J. L. (2009). A construção da identidade nacional brasileira. Revista BAKHTINIANA, 1(1), 115-126. https://revistas.pucsp.br/index.php/bakhti niana/article/view/3002.

Fonseca, M. V. (2007). A arte de construir o invisível: o negro na historiografia educacional brasileira. Revista Brasileira de História da Educação. Autores associados, $\mathrm{n}^{\mathrm{o}}$ 13. http://periodicos.uem.br/ojs/index.php/rbhe/article/view/38616

Gomes, N.L. (2008). A questão racial na escola: desafios colocados pela implementação da Lei 10.639/03. In: Moreira, A. F \& Candau, V. M. (Orgs.). Multiculturalismo: diferenças culturais e práticas pedagógicas. Petrópolis, RJ: Vozes.

Janz, R. C. (2014). Dez anos da lei 10.639/03: o que mudou nos livros didáticos de História? - Uma proposta de análise. Anais do XV Encontro Estadual de História "1964-2014: Memórias, Testemunhos e Estado", 11 a 14 de agosto de 2014, UFSC, Florianópolis - SC.

Leite, D. M. (2007). O caráter nacional brasileiro: história de uma ideologia (7a ed.), Editora Unesp.

Litz, V. G. (2009). O uso da imagem no ensino de História. Curitiba. http://www.diaadiaeducacao.pr.gov.br/portals/pde/arquivos/1402-6.pdf.

Lopes, N. (2006). Dicionário escolar afro-brasileiro. Selo Negro Edições.

Oliva, A. R. (2009). Lições sobre a África: abordagens da história africana nos livros didáticos brasileiros. Revista de história 161 (2º semestre de 2009), 213 244. http://www.revistas.usp.br/revhistoria/article/view/19124/21187.

Ribeiro, D. (1995). O povo brasileiro: a formação e o sentido do Brasil. Companhia das Letras. 
Research, Society and Development, v. 10, n. 2, e48310212798, 2021

(CC BY 4.0) | ISSN 2525-3409 | DOI: http://dx.doi.org/10.33448/rsd-v10i2.12798

Roiz, D. S \& Santos, J.R. (2016). O uso das imagens em sala de aula: reflexões sobre a implementação da lei: 10.639/03 em escolas estaduais da cidade de Amambai/MS. https://historiapt.info/a-educaco-em-perspectiva-histrica-temas-e-problemas.html?page=156.

Rüsen, J. (2010). Razão histórica. Teoria da História I: os fundamentos da ciência da história. Editora da UFPR.

Schimidt, M. A. M. dos. (2012). História do ensino de história no brasil: uma proposta de periodização. Revista História da Educação - RHE. 16 (37), 73-91. https://seer.ufrgs.br/index.php/asphe/article/view/24245.

Schimidt, M. A. M. dos S. \& Garcia, T. M. F. B. (2005). A formação da consciência histórica de alunos e professores e o cotidiano em aulas de História. Cad. Cedes. Campinas. 25(67), 297-308.

Silva Filho, J. B. (2006). História do Negro no Brasil. In. Oliveira, I. \& Siss, A. (orgs). Cadernos PENESB: População negra e Educação Escolar. (n.7) (novembro 2006) Rio de Janeiro/Niterói - Quartet/EdUFF. 